\title{
An Epidemiologic Study of Deciduous Molar Relations in Preschool Children
}

\author{
PETER F. INFANTE* \\ Center for Human Growth and Development, University of Michigan, \\ Ann Arbor, Michigan 48104, USA
}

This study indicated that distoclusion decreased significantly with age and was more prevalent in siblings of children with Class II molar relation as compared with the prevalence for the total population. Children of middle socioeconomic status (SES) and girls with Class I molar relation had prevalences of posterior crossbite significantly greater than lower SES children and boys, respectively. Finger habits were highly associated with posterior crossbite $(P<0.001)$

The influence of deciduous molar relations on tooth position and occlusion of the permanent dentition is well appreciated. Nevertheless, little epidemiologic data are available regarding factors associated with occlusal relations of the deciduous molars in preschool children. In the study of anteroposterior molar relations of preschool children, Baume ${ }^{1}$ and Sillman² observed no changes with age, whereas Humphreys and Leighton ${ }^{3}$ have reported a slight increase in the prevalence of Class II molar relation in children between the ages of 2 and 5 years. Nanda, ${ }^{4}$ however, has reported no change in the prevalence of Class II molar relation (distal step at terminal plane), but rather a significant increase with age in the prevalence of Class III molar relation (mesial step). Tremendous increments of adjustive growth have been reported to take place in children with Pierre Robin syndrome, $\overline{ }$ but

The field portion of this study was supported by Contract MC-R-390050 from the Maternal and Child Health Services, Department of Health, Education, and Welfare.

Received for publication August 12, 1974.

Accepted for publication November 22, 1974.

- Present address: Division of Chronic Diseases, Ohio Department of Health, 450 E. Town St., Columbus, Ohio 43216. a reduction in the anteroposterior discrepancy in molar relations in presumably normal children between ages 2 and 5 years has been less apparent.

Although finger habits are known to be significantly related to malocclusion ${ }^{6-9}$ and finger habits are usually reported to occur more frequently in children of more favorable socioeconomic status (SES), 6,8 some investigators have reported $\operatorname{little}^{3}$ or no association 6 between SES and malocclusion in preschool children. In view of the limited number of reports pertaining to occlusion in preschool children and the contradictory findings concerning age-changes in deciduous molar relations, a further investigation seemed appropriate. The study presented here is based on data from 680 white children, ages 2.5 to 6.0 years, who represented about 36 states and the District of Columbia.

\section{Materials and Methods}

A survey of the nutritional status of preschool children in the United States was carried out in the years 1969 and 1970. The methods of selection for the national sample $^{10}$ and for those given medical11 and dental examinations ${ }^{12}$ have been described previously. Although 957 white children were given dental examinations, for this report occlusal assessments are based only on data from children who had completed deciduous tooth emergence. Thus, data for 680 children were used for analysis. All examinations were given by one dentist (the author) with the aid of a mouth mirror and portable dental light. Occlusion was assessed while each child was biting on his or her back teeth with the jaw in centric relation. Occlusal comparisons were based on measurements of anteroposterior molar relations 
and posterior lingual crossbite. Molar relation was defined as follows: Class I, the distal surfaces of the maxillary and mandibular molars were in the same vertical plane or the mesiobuccal cusp of the maxillary second molar was in contact with the mesiobuccal groove of the mandibular second molar, or both; Class II, the distal surfaces of the mandibular second molars were posterior to the distal surfaces of the maxillary second molars; Class III, the mesiobuccal cusp of the maxillary second molar occluded with the distobuccal cusp of the mandibular second molar. Canine occlusion was used as a second reference for occlusal status using criteria similar to those of Foster and Hamilton. ${ }^{13}$ If there was a disparity in occlusal classification between canine and molar relations, the molar relation was reassessed and the final decision made on the basis of molar relation. For the purposes of calculations of prevalence, children were classificd as Class II or Class III on the basis of bilateral occurrence only. Teeth were considered in lingual crossbite when the maxillary teeth occluded in lingual relation to the mandibular teeth. Assessments for SES were based on ratings of occupation, source of income, dwelling type, and dwelling area according to the Warner Index Stratification Characteristic. ${ }^{14}$ Children were distributed among four of five SES equivalents, these being lower-lower, upperlower, lower-middle, and upper-middle, with no children classified as being in the upper SES. For the purposes of this report, children of the lower-lower and upper-lower SES were designated as lower SES only and those of the lower-middle and upper-middle SES were designated as simply middle SES.

\section{Results}

The prevalences of Class II molar relation in boys and girls were 21.4 and $16.9 \%$, respectively. Since these differences were not significant statistically, data for boys and girls were combined and the prevalence of Class II molar relation was computed by one-year age intervals as shown in Table 1 . The prevalence decreased from $26.5 \%$ in the 2-year-old to $14.1 \%$ in 5 -year-old children. The prevalence for age groups 2 and 3 years combined $(24.3 \%)$ was significantly greater $(P<0.01)$ than the prevalence for age groups 4 and 5 years combined $(15.8 \%)$ by chi-square test $\left(\chi^{2}=7.59, d f=1\right)$. There were no children in age groups 2 and 3 years with Class III molar relation, whereas 7 of 412 children $(1.7 \%)$ in age groups 4 and 5 years had Class III molar relation. The number of children with Class III molar relation was too small to allow any meaningful conclusion. These observations indicate that there was a slight increase in Class III molar relation and a significant decrease in Class II molar relation as age increased. Although these data are from cross-sectional study, the findings are compatible with a theory of horizontal mandibular catch-up growth in normal children during the preschool years.

Class II molar relation then was computed for children of middle and lower SES. The prevalence of Class II molar relation in boys of the lower SES $(21.0 \%)$ and middle SES $(21.9 \%)$ was about the same. The

TABLE 1

Prevalence of Glass iI Molar Relation by Age, boys and Girls Combined, UNITED STATES, 1969-70

\begin{tabular}{|c|c|c|c|c|c|}
\hline $\begin{array}{l}\text { Age } \\
\text { Group } \\
\text { (Year) }\end{array}$ & $\mathrm{N}$ & $\begin{array}{l}\text { No. with } \\
\text { Class II Molar } \\
\text { Relation }\end{array}$ & $\begin{array}{c}\text { Prevalence } \\
(\%)\end{array}$ & $\begin{array}{l}\text { Age Group } \\
2 \text { to } 3 \text { vs } 4 \text { to } 5 \\
\text { Prevalence } \\
(\%)\end{array}$ & $x^{2}$ \\
\hline 2 & 68 & 18 & 26.5 & \multirow{2}{*}{24.3} & \multirow{5}{*}{$7.59 *$} \\
\hline 3 & 200 & 47 & 23.5 & & \\
\hline 4 & 207 & 36 & 17.4 & \multirow[b]{2}{*}{15.8} & \\
\hline 5 & 205 & 29 & 14.1 & & \\
\hline All ages & 680 & 130 & 19.1 & & \\
\hline
\end{tabular}

\footnotetext{
$P<0.01$
} 
TABLE 2

Prevalence of Posterior lingual Crossbite in Total Sample of White Children, Ages 2.50 to 5.99 Years Combined by Socioeconomic Status (SES) and Sex, United States, 1969-70

\begin{tabular}{|c|c|c|c|c|c|c|c|}
\hline \multirow[b]{2}{*}{$\begin{array}{l}\text { Socioeconomic } \\
\text { Status }\end{array}$} & \multicolumn{2}{|c|}{ Boys } & \multicolumn{2}{|c|}{ Girls } & \multicolumn{2}{|c|}{ Both Sexes } & \multirow{2}{*}{$\begin{array}{l}\chi^{2} \text { for Low } \\
\text { vs Middle } \\
\text { SES }\end{array}$} \\
\hline & $\mathbf{N}$ & $\begin{array}{c}\text { Crossbite } \\
(\%)\end{array}$ & $\mathbf{N}$ & $\begin{array}{c}\text { Crossbite } \\
(\%)\end{array}$ & $\mathbf{N}$ & $\begin{array}{c}\text { Crossbite } \\
(\%)\end{array}$ & \\
\hline Lower SES & 176 & 2.9 & 174 & 5.2 & 350 & 4.6 & \\
\hline Middle SES & 160 & 7.5 & 170 & 11.8 & 330 & 9.7 & 0.75 \\
\hline Combined SES & 336 & 5.7 & 344 & 8.4 & 680 & 7.1 & \\
\hline$\chi^{2}$ for boys vs girls & & 1. & & & & & \\
\hline
\end{tabular}

prevalence of Class II molar relation in girls of the lower SES (18.4\%) was greater than in girls of the middle SES $(15.3 \%)$. With sex groups combined, the prevalences in lower and middle SES children were 19.7 and $18.5 \%$, respectively. The slight differences in the prevalence of Class II molar relation by SES were not significant.

The prevalence of Class II molar relation then was studied in siblings of children with Class II molar relation. Of 37 siblings who had completed deciduous tooth emergence, $13(35.1 \%)$ had Class II molar relation. If the population prevalence is assumed to be $19.1 \%$ (Table 1 ), the prevalence in the siblings is significantly greater than the expectancy $(P<0.05)$.

The prevalence of posterior lingual crossbite was computed by SES, with sex groups separate and combined, for all children (Table 2) and for children with only Class I anteroposterior molar relation (Table 3 ).
In the total sample of children, there was a greater prevalence of posterior lingual crossbite in both boys and girls of the middle SES. With sex groups combined, the difference between the prevalence of crossbite in children of the middle and lower SES was significant by chi-square test $(P<0.025)$. Although girls had a greater prevalence of posterior crossbite than boys (Table 2), with data for SES combined the difference was not significant by chi-square test $\left(x^{2}=\right.$ 1.98) until comparisons were based only on children with Class I molar relation as shown in Table $3\left(\chi^{2}=5.62, P<0.025\right)$. The difference between the sexes became significant in the latter case because seven boys with posterior crossbite who had Class II or Class III molar relations were eliminated from the numerator, whereas only one girl with Class II molar relation was eliminated. In this sample of children, posterior lingual crossbite was associated highly with

TABLE 3

Prevalence of Posterior Lingual Crossbite in 543 White Children with Class I Molar Relation, Ages 2.50 to 5.99 Years Combined, by Socloeconomic Status (SES) and Sex, United States, 1969-70

\begin{tabular}{|c|c|c|c|c|c|c|c|}
\hline \multirow[b]{2}{*}{$\begin{array}{l}\text { Socioeconomic } \\
\text { Status }\end{array}$} & \multicolumn{2}{|c|}{ Boys } & \multicolumn{2}{|c|}{ Girls } & \multicolumn{2}{|c|}{ Both Sexes } & \multirow{2}{*}{$\begin{array}{c}\chi^{2} \text { for Low } \\
\text { vs Middle } \\
\text { SES }\end{array}$} \\
\hline & $\mathbf{N}$ & $\begin{array}{c}\text { Crossbite } \\
(\%)\end{array}$ & $\mathbf{N}$ & $\begin{array}{c}\text { Crossbite } \\
(\%)\end{array}$ & $\mathbf{N}$ & $\begin{array}{l}\text { Crossbite } \\
(\%)\end{array}$ & \\
\hline Lower SES & 138 & 2.9 & 129 & 6.5 & 277 & 4.7 & \multirow[t]{3}{*}{ 5.93* } \\
\hline Middle SES & 122 & 6.6 & 144 & 13.2 & 266 & 10.2 & \\
\hline Combined SES & 260 & 4.6 & 283 & 9.9 & 543 & 7.4 & \\
\hline$\chi^{2}$ for boys vs $g$ & \multicolumn{4}{|c|}{$5.62^{*}$} & & & \\
\hline
\end{tabular}

$* P<0.025$. 
finger sucking. Sixteen of the 40 children $(40 \%)$ with Class I molar relation who had a posterior crosslite had finger habits. Of the remaining 503 children with Class I molar relation and no posterior crossbite, only $74(14.7 \%$ ) had finger habits. The difference in habits between the two groups was significant $\left(x^{2}=17.1, P<0.001\right)$.

\section{Discussion}

Although these findings are based on cross-sectional investigation, the significant reductions in the prevalence of Class II molar relation with advancing age suggest that a reduction in anteroposterior discrepancy in molar relations may take place in children between the ages of 2 and 5 years. There was a $46 \%$ reduction in the prevalence in children between these ages. Some investigators have reported little or no change in molar relations with increasing age, ${ }^{1-3}$ whereas $\mathrm{Nanda}^{4}$ has reported a significant increase in the prevalence of Class III molar relations (mesial step) and a significant reduction in overbite and overjet as children became older. Because of differences in criteria for the assessment of molar relations, comparisons of prevalence calculations from different studies are difficult to make. Many of the children that Nanda 4 classified as having Class III molar relation would probably have been classified as Class $I$ in this study. The findings of Nanda, 4 however, are in a similar direction to those reported here. Both studies suggest a mesial shift of the mandible in children between the ages of 2 and 6 years, which may have been caused by growth.

The findings of a significantly greater prevalence of Class II molar relation in siblings of children with distocclusion as compared with the total population are of the same magnitude and direction as those reported by Humphreys and Leighton. ${ }^{3}$

With regard to sex and SES, Myllarniemi ${ }^{15}$ has reported that several investigators have observed a greater prevalence of sucking habits in girls; others 6,8 have reported a greater prevalence of sucking habits in children of more favorable SES as compared with boys and children of the lower SES. The effect of digital sucking on the narrowing of the maxillary arch also has been well established. ${ }^{5,8,16}$ Therefore, the finding that girls and children of middle SES had significantly greater percentages with crossbite related to finger habits was not unexpected. It is also noteworthy that whereas finger habits decreased with age, the prevalence of posterior crossbite remained about the same. These data are not shown in the tables. Although discontinuation of active sucking habits before age 6 years has been reported to result in little additional risk of malocclusion, 7,8 the findings in this study suggest that discontinuation of digital sucking may not result in the reestablishment of normal occlusion in the posterior segment of the arch.

\section{Conclusions}

An epidemiologic study of deciduous molar relations in 680 United States white children indicated that the prevalence of Class II molar relation decreased significantly with advancing age and that siblings of children with Class II molar relation had a prevalence of Class II molar relation significantly greater than the prevalence for the total population. The prevalence of posterior lingual crossbite was significantly greater in children of middle SES and in girls as compared with children of lower SES and boys, respectively. Oral habits were highly associated with posterior lingual crossbite.

\section{References}

1. Baume, L.J.: Physiological Tooth Migration and Its Significance for the Development of Occlusion, J Dent Res 29: 123-132, 1950.

2. Sillman, J.H.: Serial Study of Occlusion (Birth to Ten Years of Age), Am J Orthod 34: 969-989, 1948.

3. Humphreys, H.F.; and Leighton, B.C.: A Survey of Anteroposterior Abnormalities of the Jaws in Children Between the Ages of Two and Five and a Half Years of Age, $B r$ Dent $J$ 88: 3-15, 1950.

4. NANDA, R.S.: Age Changes in the Occlusal Pattern of Deciduous Dentition, $J$ Dent Res 52: 221-224, 1973.

5. Graber, T.M.: Orthodontics Principles and Practice, 2nd ed, Philadelphia: W. B. Saunders Co, 1966, pp 261-323.

6. Calisti, L.P.J.; Cohen, M.M.; and Fales, M.H.: Correlation Between Malocclusion, Oral Habits, and Socio-Economic Level of Preschool Children, J Dent Res 39: 450-454, 1960.

7. Myllarniemi, S.: Oral and Dental State in Helsinki Preschool Children V. Oral Habits and Occlusion, Proc Finn Dent Soc 69: 157$163,1973$.

8. Popovich, F.: The Prevalence of Sucking 
Habits and Its Relationship to Malocclusion, Oral Health 57: 498-505, 1967.

9. Holm, A.-K., and ARvidsson, S.: Oral Health in Preschool Swedish Children, Odontol Revy 25: 81-98, 1974.

10. KISH, L., and HEss, I.: The Survey Research Center's National Sample for Dwellings, Institute for Social Research Publication No. 2315, Ann Arbor, University of Michigan, 1965.

I1. OWEN, G.M.; KraM, K.M.; Garry, P.J; LowE, J.E.; and Lubin, A.H.: A Study of Nutritional Status of Preschool Children in the United States, 1968-1970, Pediatrics 53 (suppl) : 579-646, 1974.

12. Infante, P.F., and OWEN, G.M.: Relation of the Chronology of Deciduous Tooth Emergence to Height, Weight and Head Circumference in Children, Arch Oral Biol 18: $1411-1417,1973$.

13. Foster, T.D., and Hamilton, M.C.: OCclusion in the Primary Dentition, $B r$ Dent $J$ 126: 76-79, 1969.

14. Warner, W.L.: Social Class in America, New York: Harper and Row, 1960.

15. Myllarniemi, S.: Oral and Dental State in Helsinki Preschool Children III. Prevalence of Dummy and Finger Sucking Habits, Proc Finn Dent Soc 69: 47-51, 1973.

16. MOYERS, R.E.: Handbook of Orthodontics, 3rd ed, Chicago: Year Book Medical Publishers, 1973, p 255. 